\title{
Effectiveness of psychoeducational support on quality of life in early-stage breast cancer patients: a systematic review and meta-analysis of randomized controlled trials
}

\author{
Ayako Matsuda $\cdot$ Kazue Yamaoka • \\ Toshiro Tango - Tomohiro Matsuda • \\ Hiroshi Nishimoto
}

Accepted: 11 June 2013/Published online: 24 July 2013

(C) The Author(s) 2013. This article is published with open access at Springerlink.com

\begin{abstract}
Purpose Most breast cancer patients receive psychosocial support interventions. However, the effectiveness of these interventions has not yet been clarified. Quality of life (QOL) was an important construct that should be considered when assessing these interventions. The purpose was to evaluate the effectiveness of psychosocial and especially psychoeducational support interventions for early-stage breast cancer patients since the follow-up was bound up to 6 months after finishing the intervention.

Methods We conducted a systematic review and metaanalysis to identify randomized controlled trials with earlystage breast cancer patients receiving psychosocial (psychoeducational and other) support in which QOL was measured as a treatment outcome. We compared mean differences at less than 6 months post-intervention with a control group. The primary outcome was Global Health Status/QOL scale (Global QOL), and secondary outcomes were the subscales of QOL.

Results No significant effect was observed for Global QOL; however, individuals receiving psychosocial support scored higher on the Breast Cancer Symptoms subscale.
\end{abstract}

\footnotetext{
A. Matsuda $(\square) \cdot$ T. Matsuda $\cdot$ H. Nishimoto

Surveillance Division, Center for Cancer Control and Information Services, National Cancer Center, 5-1-1 Tsukiji, Chuo-ku, Tokyo 104-0045, Japan

e-mail: amatsuda@ncc.go.jp

K. Yamaoka

Graduate School of Public Health, Teikyo University,

2-11-1 Kaga, Itabashi-ku, Tokyo 173-8605, Japan

T. Tango

Center for Medical Statistics, 2-9-6 Higashi-Shinbashi,

Minato-ku, Tokyo 105-0021, Japan
}

For psychoeducational support in the psychosocial support, significant effect was observed on the Emotional subscale. Conclusions Our analysis strengthens the evidence of the effectiveness of psychosocial support in improving breast cancer symptoms and psychoeducational support in improving emotional well-being within 6 months postintervention.

Keywords Quality of life - Meta-analysis · Breast cancer · Psychosocial support · Psychoeducational support

\section{Introduction}

Breast cancer is the most frequently diagnosed cancer among women in global cancer statistics [1]. Incidence rates are much higher in more developed countries, and observed improvements in breast cancer survival over recent decades have been attributed to the systematic use of adjuvant therapies [2]. However, breast cancer patients may experience many manifestations resulting from the primary disease and/or treatment for the disease, and face issues related to simultaneously dealing with a multitude of physical and psychological symptoms [3].

Interventions after primary treatment for breast cancer should have several aims. Psychosocial support can provide assistance and encouragement to individuals with physical or emotional disabilities. There are many research papers on the effectiveness of psychosocial interventions on quality of life (QOL). However, most of the interventions aimed at physical symptoms have beneficial effects on QOL at varying follow-up periods [4, 5]. Results of a meta-analysis revealed that behavioral techniques and physical exercise improve psychosocial functioning and QOL [6]. The psychosocial aspect includes interventions 
described as psychological, psychotherapeutic, psychoeducational, or psychosocial [7]. Psychosocial constructs that have the strongest association with QOL are stress, affect, and cognitive appraisal [8]. Although to improve emotional well-being is important, the effectiveness of interventions other than exercise has not been clarified in QOL. The psychosocial interventions are wide ranging (e.g., psychoeducational support, cognitive behavioral therapy, and emotional expression). One of the most effective psychosocial approaches to cancer patients is psychoeducation [9]. The psychoeducational interventions in psychosocial interventions specifically address emotional concerns arising from the distress that can be caused by being overwhelmed or confused [7]. We considered that it was important to evaluate a focus on psychoeducational interventions in psychosocial interventions. In many studies, the majority of the women with breast cancer reported needing increased educational support [10]. Recent meta-analysis by Cochrane review examined the effect psychoeducational intervention on QOL as a part of psychosocial support interventions for cancer patients, and the psychoeducational interventions produced small positive significant effects on QOL by the result of only one study [7].

The purpose in this study was to evaluate the effectiveness of psychosocial and especially psychoeducational support interventions to improve QOL for early-stage breast cancer patients since the follow-up was bound up to 6 months after finishing the intervention. We conducted a meta-analysis to evaluate the effectiveness of psychosocial support interventions other than exercise for early-stage breast cancer patients, paying particular attention to their QOL. Additionally, we considered QOL in psychosocial support that was subdivided into psychoeducational or other psychosocial support. The results of this study are expected to provide useful information for early-stage breast cancer patients receiving psychosocial support, taking into consideration QOL.

\section{Materials and methods}

Study design

This study is a systematic literature review and metaanalysis.

\section{Search for trials}

Trials were identified by an electronic search of the PubMed database and the Cochrane Central Register of Controlled Trials (CENTRAL) database. Search terms used were "quality of life" [MeSH Terms] AND "breast neoplasms" [MeSH Terms] AND "social support," with searches limited to publications of randomized controlled trials (RCTs) in humans.

\section{Selection of trials}

We conducted a literature search using the Cochrane Database and PubMed database (data from September 1988 to January 2012) to identify RCTs on breast cancer interventions in which QOL was measured as a treatment outcome.

Trials were eligible for inclusion in the meta-analysis if they compared an intervention group receiving psychosocial support with a control group in early-stage breast cancer patients and if they reported QOL data using a QOL questionnaire. All inclusion and exclusion criteria for selection of trials are shown in Table 1. The trials were then hand searched according to these criteria.

\section{Data extraction}

Among the QOL scales, we focused on Global Health Status/QOL scale (Global QOL) and the 5 subscales [Breast Cancer Symptoms, Physical, Emotional (Psychological), Social, and Functional] that were most often assessed across studies. We only used QOL data collected at baseline and less than 6 months after the start of intervention to observe the effectiveness of interventions. In the assessment of risk of bias in included studies, the review authors worked to assess the methodological quality

Table 1 Inclusion/exclusion criteria for selected trials

\begin{tabular}{ll}
\hline Inclusion criteria & Exclusion criteria \\
\hline $\begin{array}{l}\text { Randomized controlled clinical } \\
\text { trials }\end{array}$ & $\begin{array}{c}\text { Studies including patients with } \\
\text { metastatic or advanced stage } \\
\text { cancer } \\
\text { Studies on breast cancer }\end{array}$ \\
$\begin{array}{c}\text { Studies including patients with } \\
\text { psychiatric problems }\end{array}$ \\
$\begin{array}{l}\text { Studies comparing a group } \\
\text { receiving social support with a } \\
\text { control group }\end{array}$ & Not an intervention study
\end{tabular}

Intervention studies that included exercise as social support

Studies not reporting adequate information on the randomization process in the "Materials and methods" or "Results" section

Studies not reporting healthrelated quality of life (HRQOL) data using a QOL questionnaire

\footnotetext{
${ }^{a}$ Social support systems provide assistance and encouragement to individuals with physical or emotional disabilities so they can better cope
} 
Table 2 Summary of characteristics in selected RCTs

\begin{tabular}{|c|c|c|c|c|c|c|c|c|}
\hline \multirow{2}{*}{$\begin{array}{l}\text { Author } \\
\text { Sandgren } \\
{[20]^{\mathrm{a}}}\end{array}$} & \multirow{2}{*}{$\begin{array}{l}\text { Years } \\
2003\end{array}$} & \multirow{2}{*}{$\begin{array}{l}\text { Country } \\
\text { USA }\end{array}$} & \multirow{2}{*}{$\begin{array}{l}\text { Follow- } \\
\text { up } \\
\text { (month) } \\
5\end{array}$} & \multirow{2}{*}{$\begin{array}{l}n \text { (intervention/ } \\
\text { control) }(610 / \\
549) \\
78 / 55\end{array}$} & \multicolumn{2}{|c|}{ Social support intervention } & \multirow{2}{*}{$\begin{array}{l}\text { Period of the } \\
\text { intervention } \\
\text { (months) }\end{array}$} & \multirow{2}{*}{$\begin{array}{l}\text { Sessions } \\
6\end{array}$} \\
\hline & & & & & $\begin{array}{l}\text { Psychoeducational } \\
\text { support }\end{array}$ & $\begin{array}{l}\text { Health education, emotional } \\
\text { expression }\end{array}$ & & \\
\hline $\begin{array}{c}\text { Meneses } \\
{[18]}\end{array}$ & 2007 & USA & 3,6 & $125 / 131$ & & $\begin{array}{l}\text { Breast Cancer Education } \\
\text { Intervention (BCEI) } \\
\text { psychoeducational support }\end{array}$ & 6 & 8 \\
\hline $\begin{array}{c}\text { Beatty } \\
{[15]}\end{array}$ & 2010 & Australia & 3,6 & $25 / 24$ & & $\begin{array}{l}\text { Self-help workbook (each chapter } \\
\text { containing educational } \\
\text { information on common } \\
\text { medical and psychosocial } \\
\text { issues) }\end{array}$ & 6 & \\
\hline $\begin{array}{l}\text { Gustafson } \\
{[21]}\end{array}$ & 2001 & USA & 2,5 & $121 / 125$ & $\begin{array}{l}\text { Other psychosocial } \\
\text { Support }\end{array}$ & $\begin{array}{l}\text { Comprehensive Health } \\
\text { Enhancement Support System } \\
\text { (CHESS) }\end{array}$ & 5 & \\
\hline $\begin{array}{l}\text { Sandgren } \\
{[20]^{\mathrm{a}}}\end{array}$ & 2003 & USA & 5 & $89 / 55$ & & $\begin{array}{l}\text { Health education, emotional } \\
\text { expression }\end{array}$ & 3 & 6 \\
\hline Owen [19] & 2005 & USA & 3 & $62 / 62$ & & Online coping program & 3 & \\
\hline $\begin{array}{l}\text { Gellaitry } \\
\text { [17] }\end{array}$ & 2010 & UK & $1,3,6$ & $38 / 42$ & & $\begin{array}{l}\text { Writing intervention (emotional } \\
\text { disclosure, cognitive appraisal, } \\
\text { benefit finding, looking to the } \\
\text { future) }\end{array}$ & 6 & 4 \\
\hline $\begin{array}{r}\text { Salzer } \\
{[16]}\end{array}$ & 2010 & USA & 4,12 & $50 / 26$ & & Internet peer support & 12 & \\
\hline $\begin{array}{l}\text { Cousson- } \\
\text { Gelie } \\
{[14]}\end{array}$ & 2011 & France & $1^{\mathrm{b}}$ & $22 / 29$ & & $\begin{array}{l}\text { Specific intervention (a specific } \\
\text { psychosocial intervention) }\end{array}$ & 1 & 8 \\
\hline
\end{tabular}

a This study compared separately the effectiveness of health education and emotional expression interventions to that of standard care

b After eight sessions (or 1 month for the control group)

(random allocation, allocation concealment, blinding, and loss to follow-up) [7] of each selected study.

\section{Statistical analysis}

We compared mean differences in Global QOL and subscales scores at less than 6 months post-intervention in earlystage breast cancer patients receiving psychosocial support (intervention group) and no such support (control group). The control group received normal care. These differences between groups were treated as effect sizes in our metaanalysis. After that, psychosocial support was then subdivided into psychoeducational or other psychosocial support.

Overall estimates were examined using a random-effects model (DerSimonian-Laird method) [11] and a fixedeffects model (general variance-based method). The $\chi^{2}$ test was used to assess heterogeneity among trials. Considering that the fixed-effects model is useful only under conditions of homogeneity and that the power of statistical tests of heterogeneity is low, we planned to use the random-effects model as the primary method irrespective of the test result for heterogeneity. A fixed-effects model was used for sensitivity analysis. S-plus and $\mathrm{R}$ programs $[12,13]$ were used for the estimation of the random-effects and fixedeffects models. A favorable outcome from psychosocial support (psychoeducational or other psychosocial support) was reflected when the mean for QOL was greater for the intervention group than for the control group.

All scale scores linearly transformed to a 0-100 scale, with higher scores indicating more positive outcomes. In this study, a statistical test with a $p$ value less than 0.05 (two-side) was considered significant.

\section{Results}

Study characteristics

The process of study selection is illustrated in Fig. 1. Potentially relevant articles $(n=250)$ were identified from the search of the electronic databases. After this initial screening, no RCT articles $(n=211)$ were excluded leaving 39 articles. We identified 8 trials [14-21] using the exclusion criteria shown in Table 1. The study by Sandgren et al. [20] used two types of psychosocial support interventions (health education and emotional expression). Each was treated as an 
independent intervention. The trials reported QOL data using the European Organization for Research and Treatment of Cancer Core Questionnaire (EORTC QLQ-C30) [22], Functional Assessment of Cancer Therapy-Breast (FACT-B) [23], or Quality of Life-Cancer Survivors (QOLCS) [24] (Table 3). The EORTC QLQ-C30 and FACTGeneral (FACT-G), probably the two most widely used oncological QOL instruments, were subjected to equating [25]. In both the FACT-G and QOL-CS developed by Cella, there is a moderate to strong correlation between associated subscales including QOL-CS Physical to FACT Physical, QOL-CS Psychological to FACT Emotional, QOL-CS Social to FACT Social, and overall QOL-CS to the FACT-G [26]. The FACT-Breast (FACT-B) that indicates Global QOL in breast cancer patients comprises the FACT-G plus the Breast Cancer Symptoms (BCS) subscale, which contains items specific to QOL in these patients. The standard deviation was taken from a study of the reliability and validity of the FACT-B [23] and QOL-CS [24] if it was not reported in the literature. In trials by Meneses et al. [27], we removed this study because the survivors in this study were a subset of the larger group study [18]. We considered the data in trials by Park et al. [28] not appropriate because the standard deviation of the FACT-B total was approximately similar to that of the subscale scores in that study [28] and was considerably smaller compared with that of other trials [14-21]. Characteristics of the selected 8 trials (Table 2) and QOL scores of these studies (Table 4) have been summarized. In total, 1,159 patients were randomly selected, with 610 receiving psychosocial support: psychoeducational support (228 patients) and other psychosocial support (382 patients). A total of 549 patients were in control groups. In the selected 8 trials, the methodological quality was insufficient information to assess low or high risk of bias.

QOL

In all trials, analysis showed no evidence of heterogeneity among studies for Global QOL $(p=0.327)$. The mean difference in Global QOL was estimated as 0.968 (95\% CI 0.721 to $2.656, p=0.261$ ) by the random-effects model and did not differ significantly between the psychosocial support intervention group and control group (Table 4; Fig. 2). In the 5 subscales, individuals receiving support scored higher on the BCS (mean difference 3.110, $95 \%$ CI 0.504-5.716, $p=0.019$ ) subscale of QOL (Table 4; Fig. 3).

Psychoeducational support and other psychosocial support

Analysis of Global QOL related to psychoeducational support in 3 trials showed no evidence of heterogeneity among studies $(p=0.295)$. The mean difference in Global

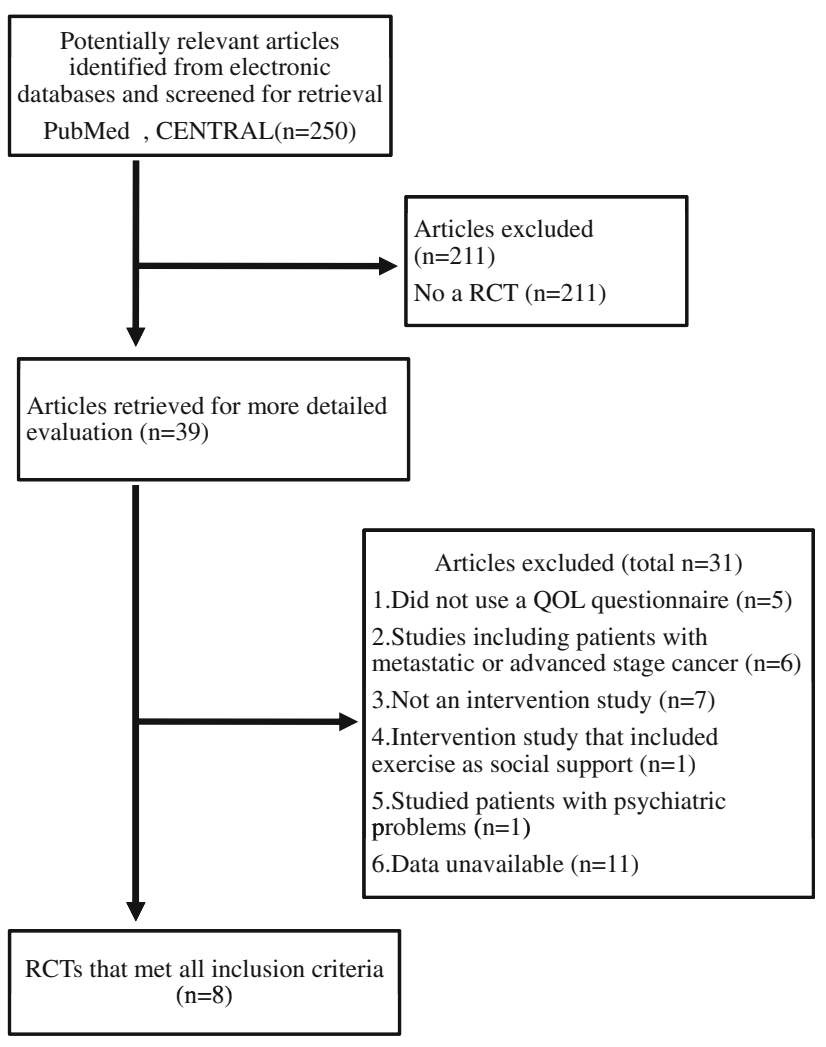

Fig. 1 Systematic review flow chart. $n$ number of articles, CENTRAL Cochrane Central Register of Controlled Trials, RCT randomized controlled trial, $Q O L$ quality of life

QOL was estimated as $1.008(95 \% \mathrm{CI}-1.775$ to 3.790 , $p=0.478$ ) by the random-effects model, not a statistically significant difference between psychoeducational support intervention and control groups (Table 4; Fig. 2). For the subscales, individuals receiving support scored highest on the Emotional subscale (mean difference 4.167, $95 \% \mathrm{CI}$ $0.760-7.574, p=0.017$ ) of QOL (Table 4; Fig. 4). The BCS and Functional Well-Being subscale were each reported in only one study.

Regarding Global QOL related to other types of psychosocial support in 5 trials, analysis showed no evidence of heterogeneity among studies $(p=0.230)$. The mean difference in Global QOL was estimated as 0.620 (95 \% CI 1.957 to $3.197, p=0.637$ ) by the random-effects model, not a statistically significant difference between other psychosocial support interventions and control groups (Table 4; Fig 2). For the subscales, individuals receiving support scored highest on the BCS items (mean difference 3.540, $95 \%$ CI 0.641-6.439, $p=0.017$ ) of QOL (Table 4; Fig 3).

\section{Discussion}

Our meta-analysis provided the evidence that the psychosocial support was effective in improving breast cancer 


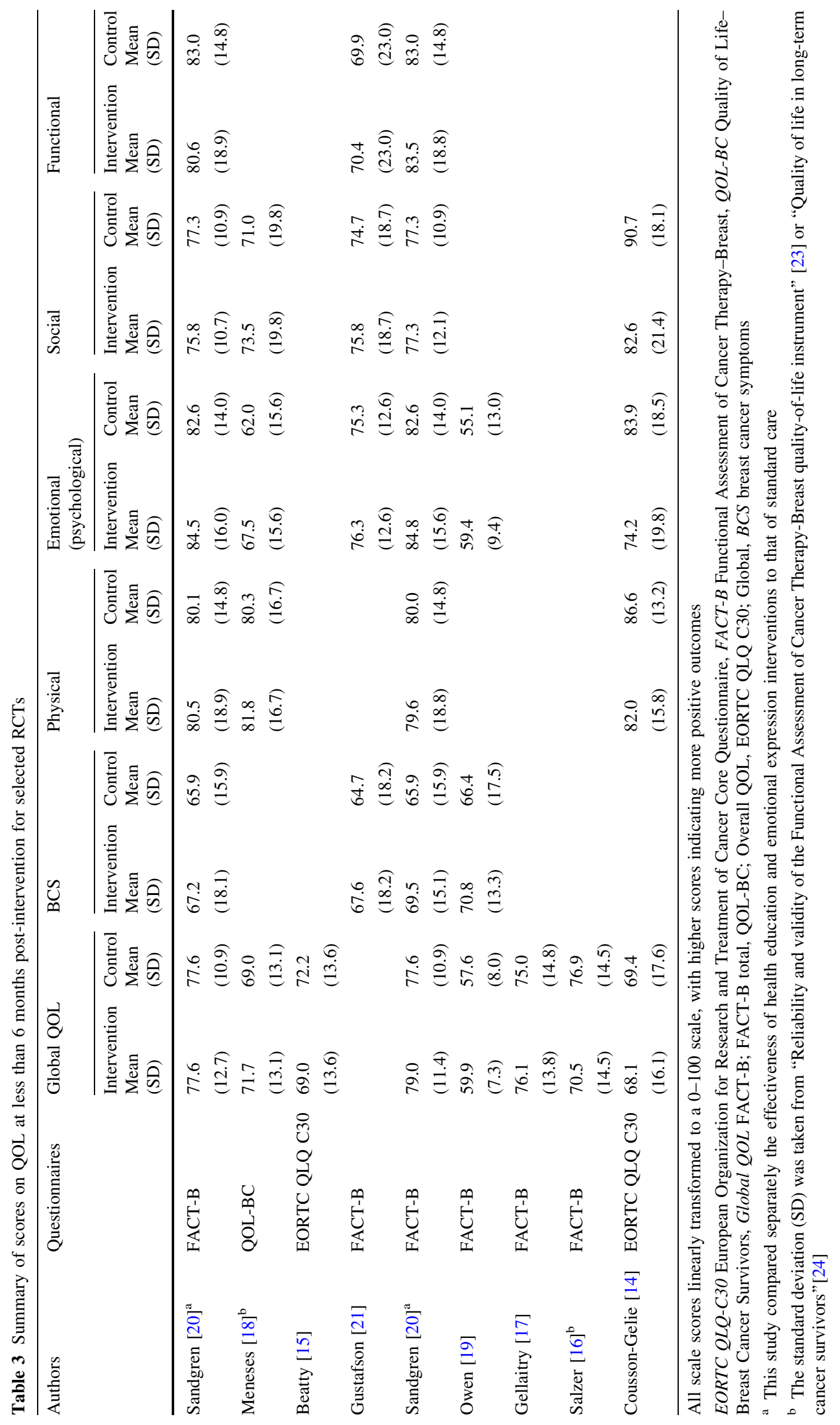




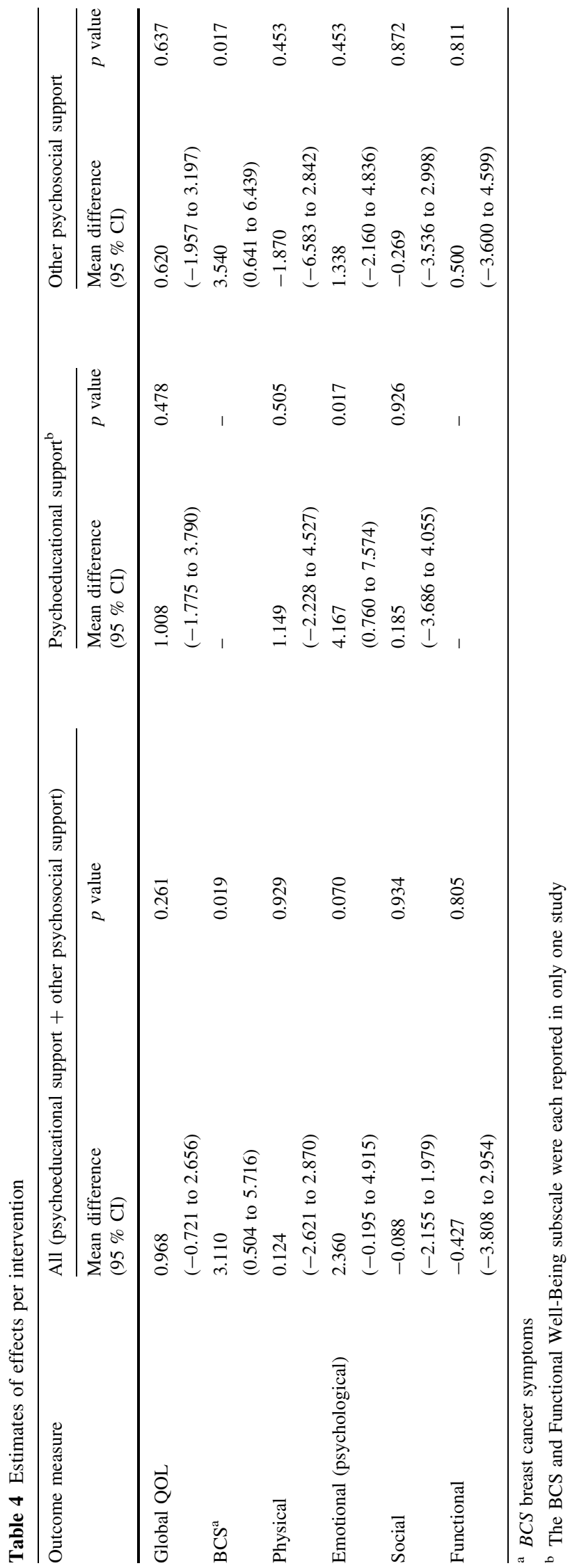

symptoms (mean difference 3.110, $95 \%$ CI 0.504-5.716, $p=0.019)$ within 6 months post-intervention. The psychoeducational support in the psychosocial support was effective in increasing emotional well-being (mean difference 4.167, $95 \%$ CI 0.760-7.574, $p=0.017$ ). With regard to different types of psychosocial support, higher emotional well-being was reported within 6 months post-intervention as a result of psychoeducational support, but not other types of psychosocial support. We did not conduct a metaanalysis regarding psychoeducational support related to breast cancer symptoms because the scale of breast cancer symptoms was reported in only one study. However, we posit that psychoeducational support was effective in improving the symptoms because individuals receiving it scored higher on the BCS, indicating greater QOL specific to breast cancer [20].

A previous meta-analysis indicated that physical exercise interventions improve QOL in breast cancer patients and survivors [6]. In contrast, this meta-analysis showed that psychosocial support interventions did not provide a significant benefit in terms of improved Global QOL in early-stage breast cancer patients. The result of Cochrane review [7] showed similar result. Namely, no significant effects were observed for QOL, while the psychoeducational interventions produced small positive significant effects on QOL [7]. However, the result was based on only one study and they did not examine the effects on subscales of QOL. For the results of the subscales, we suggested the effectiveness of psychosocial support in improving breast cancer symptoms and psychoeducational support in improving emotional well-being. Psychosocial support is an important intervention for cancer patients because stress-related psychosocial factors can have an adverse effect on cancer outcomes [29]. Specially, psychoeducation was shown to cause positive changes in levels of adjustment to cancer in breast cancer patients [9]. Chan et al. [30] also described that psychoeducational intervention was a promising treatment for relieving the symptom cluster and each of the individually assessed symptoms. Furthermore, Rottmann et al. [31] found a significant association between education and self-efficacy that was a significant predictor of emotional well-being in breast cancer patients.

In this meta-analysis, Global QOL and subscale scores tended to improve as a result of psychosocial support interventions. Therefore, it is important to assess QOL of breast cancer patients who receive psychosocial support. QOL is increasingly recognized as a major end point in medical care [32]. The US Food and Drug Administration welcomes the opportunity to explore with investigators the use of QOL instruments in the design of cancer clinical trials [33]. Information regarding QOL is invaluable in understanding the full impact of treatment differences on 
Fig. 2 Forest plot of mean scores of patients receiving psychosocial support psychosocial support) with $95 \%$ CI for each study, overall for several models (circles represent cumulative metaanalysis) difference in Global QOL (psychoeducational and other

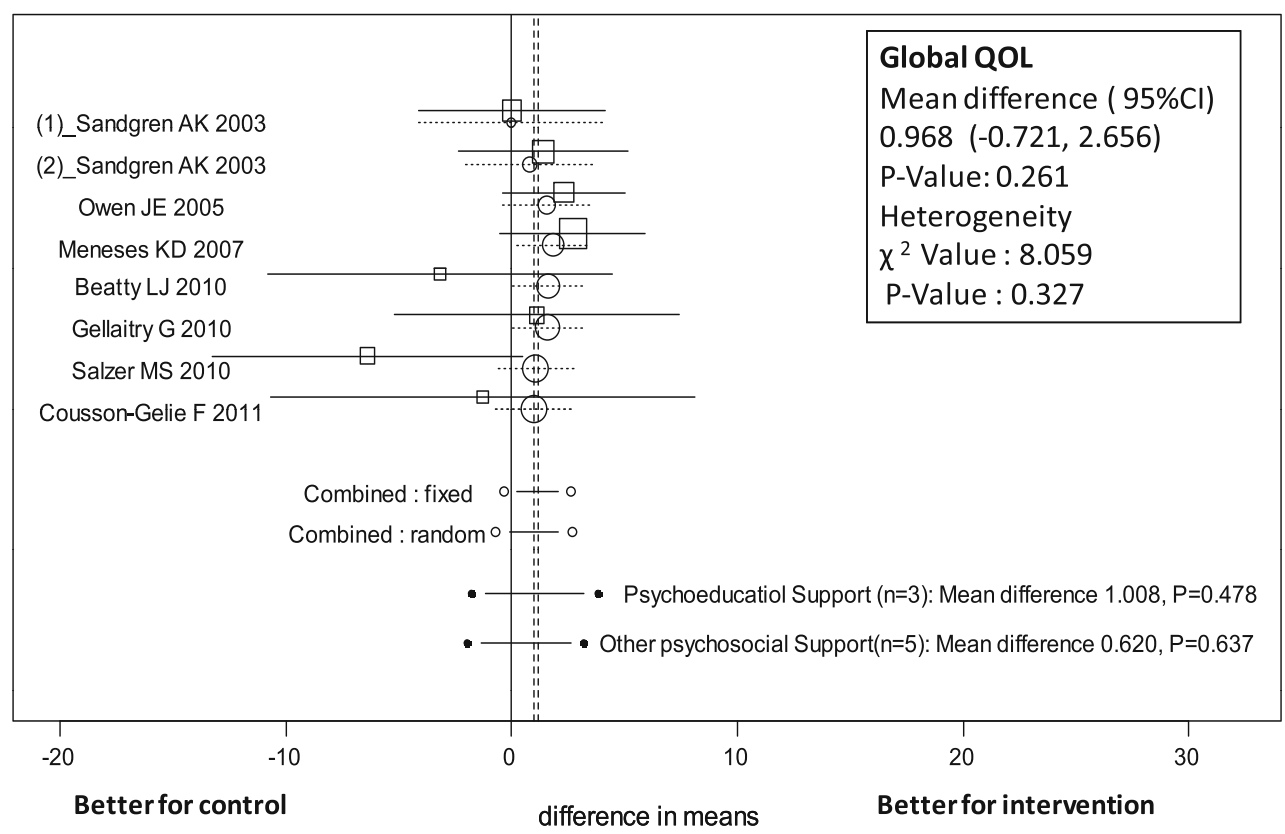

Fig. 3 Forest plot of mean difference in Breast Cancer Symptoms (BCS) subscale scores of patients receiving psychosocial support with $95 \%$ CI for each study, overall for several models (circles represent cumulative metaanalysis)

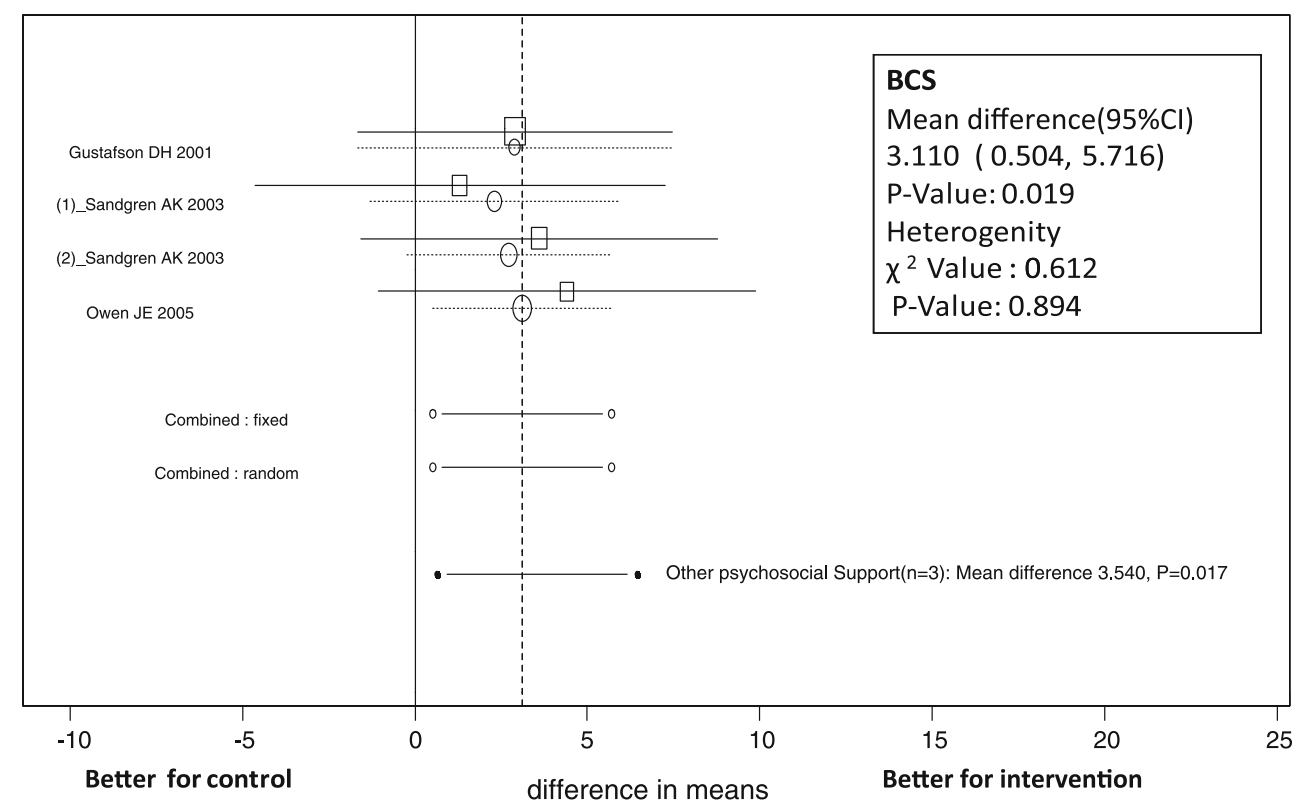

patient outcomes [34], and enhanced understanding of patient QOL can help improve clinical care [35].

We speculate that there may be differences in the effectiveness of psychosocial support interventions based on how they are administered. In 3 studies about psychoeducational support $[15,18,20]$, the interventions consisted of individual face-to-face education. In 3 studies in other psychosocial support group, the interventions consisted of computer support $[16,19,21]$. In this meta-analysis, only psychoeducational support was effective in improving emotional well-being within 6 months post-intervention. Interventions for early-stage breast cancer patients have frequently combined elements of psychoeducational and other psychosocial support, stress management techniques, and cognitive behavioral therapy [36, 37]. In a study by Grunfeld et al. [38], compilation of survivorship care plans and a psychoeducational session were undertaken in a pragmatic trial that was consistent with usual practices and feasible to implement within time and human resource constraints. It is important to examine whether interventions need to combine psychoeducational, emotional, and physical support while considering timing of such interventions.

The measurement of outcomes is more complex in psychosocial research than in most drug-based studies and 
Fig. 4 Forest plot of mean difference in Emotional subscale scores of patients receiving psychosocial support (psychoeducational and other psychosocial support) with $95 \%$ CI for each study, overall for several models (circles represent cumulative metaanalysis)

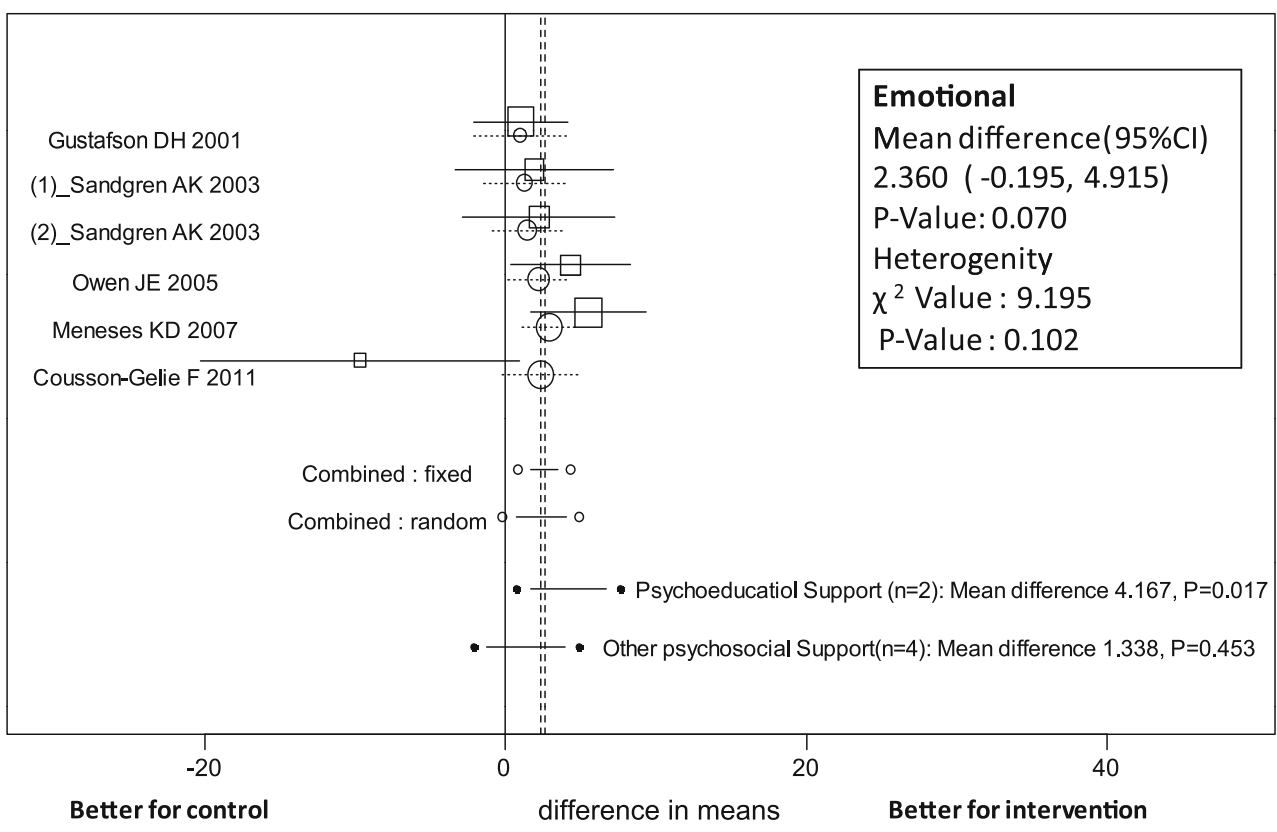

A second limitation is the variability in psychosocial support programs. Considering the heterogeneity, we used a random-effects model as the primary analysis and classified psychosocial support into two types: psychoeducational and other psychosocial support. Although the quality and content of psychosocial support programs varied, the results indicated that psychoeducational support was effective.

A third limitation is that this meta-analysis included a small number of subjects compared with previous studies [4-6] (610 patients vs. 549 controls in our study). However, some of the studies were pilot studies.

A fourth limitation is that some of the studies did not report any subscales scores. This could lead to conservative $p$ values. However, our results suggested significant associations with some QOL measures.

Furthermore, even though our search method included a systematic review and added hand search, we could have inadvertently missed eligible studies. The results should be interpreted carefully considering a risk of bias across studies.

\section{Conclusions}

Our analysis strengthens the evidence of the effectiveness of psychosocial support in improving breast cancer symptoms and psychoeducational support in improving emotional well-being within 6 months post-intervention. However, further long-term interventions may be needed to examine the effectiveness of other types of psychosocial support on improving the QOL of early-stage breast cancer patients. 
In the future, research should focus on evaluating the effectiveness of psychosocial support interventions considering long-term outcomes and examine the influence of such interventions on survival time in cancer patients.

Acknowledgments This study was financially supported by the Ministry of Education, Culture, Sports, Science and Technology in Japan Grant-in-Aid for Scientific Research Grant B in 2012 (Grant No. 24701038).

Open Access This article is distributed under the terms of the Creative Commons Attribution License which permits any use, distribution, and reproduction in any medium, provided the original author(s) and the source are credited.

\section{References}

1. Jemal, A., Bray, F., Center, M. M., Ferlay, J., Ward, E., \& Forman, D. (2011). Global cancer statistics. CA: A Cancer Journal for Clinicians, 61(2), 69-90.

2. Youlden, D. R., Cramb, S. M., Dunn, N. A., Muller, J. M., Pyke, C. M., \& Baade, P. D. (2012). The descriptive epidemiology of female breast cancer: An international comparison of screening, incidence, survival and mortality. Cancer Epidemiology, 36(3), 237-248.

3. Denieffe, S., \& Gooney, M. (2011). A meta-synthesis of women's symptoms experience and breast cancer. European Journal of Cancer Care (Engl), 20(4), 424-435.

4. Mishra, S. I., Scherer, R. W., Geigle, P. M., Berlanstein, D. R., Topaloglu, O., Gotay, C. C., et al. (2012). Exercise interventions on health-related quality of life for cancer survivors. Cochrane Database of Systematic Reviews, 8, CD007566.

5. Mishra, S. I., Scherer, R. W., Snyder, C., Geigle, P. M., Berlanstein, D. R., \& Topaloglu, O. (2012). Exercise interventions on health-related quality of life for people with cancer during active treatment. Cochrane Database of Systematic Reviews, 8, CD008465.

6. Duijts, S. F., Faber, M. M., Oldenburg, H. S., van Beurden, M., \& Aaronson, N. K. (2011). Effectiveness of behavioral techniques and physical exercise on psychosocial functioning and healthrelated quality of life in breast cancer patients and survivors-a meta-analysis. Psychooncology, 20(2), 115-126.

7. Galway, K., Black, A., Cantwell, M., Cardwell, C. R., Mills, M., \& Donnelly, M. (2012). Psychosocial interventions to improve quality of life and emotional wellbeing for recently diagnosed cancer patients. Cochrane Database of Systematic Reviews, 11, CD007064.

8. Chan, R., Brooks, R., Steel, Z., Heung, T., Erlich, J., Chow, J., et al. (2012). The psychosocial correlates of quality of life in the dialysis population: A systematic review and meta-regression analysis. Quality of Life Research, 21(4), 563-580.

9. Dastan, N. B., \& Buzlu, S. (2012). Psychoeducation intervention to improve adjustment to cancer among Turkish stage I-II breast cancer patients: a randomized controlled trial. Asian Pacific Organization for Cancer Prevention, 13(10), 5313-5318.

10. Montgomery, M., \& McCrone, S. H. (2010). Psychological distress associated with the diagnostic phase for suspected breast cancer: systematic review. Journal of Advanced Nursing, 66(11), 2372-2390.

11. Petitti, D. B. (2000). Meta-analysis, decision analysis, and costeffectiveness analysis (pp. 116-117). Oxford, NY: Oxford University Press.

12. Spector, P. (1994). An introduction to $S$ and S-Plus. Belmont, CA: Duxbury Press.
13. Tango, T. (2009). An introduction to meta-analysis; Medical statistical science series 4 (pp. 99-101). Tokyo: Asakura Bookstore.

14. Cousson-Gélie, F., Bruchon-Schweitzer, M., Atzeni, T., \& Houede, N. (2011). Evaluation of a psychosocial intervention on social support, perceived control, coping strategies, emotional distress, and quality of life of breast cancer patients. Psychological Reports, 108(3), 923-942.

15. Beatty, L. J., Koczwara, B., Rice, J., \& Wade, T. D. (2010). A randomised controlled trial to evaluate the effects of a self-help workbook intervention on distress, coping and quality of life after breast cancer diagnosis. Medical Journal of Australia, 193(5 Suppl), S68-S73.

16. Salzer, M. S., Palmer, S. C., Kaplan, K., Brusilovskiy, E., Ten Have, T., Hampshire, M., et al. (2010). A randomized, controlled study of internet peer-to-peer interactions among women newly diagnosed with breast cancer. Psychooncology, 19(4), 441-446.

17. Gellaitry, G., Peters, K., Bloomfield, D., \& Horne, R. (2010). Narrowing the gap: the effects of an expressive writing intervention on perceptions of actual and ideal emotional support in women who have completed treatment for early stage breast cancer. Psychooncology, 19(1), 77-84.

18. Meneses, K. D., McNees, P., Loerzel, V. W., Su, X., Zhang, Y., \& Hassey, L. A. (2007). Transition from treatment to survivorship: effects of a psychoeducational intervention on quality of life in breast cancer survivors. Oncology Nursing Forum, 34(5), $1007-1016$

19. Owen, J. E., Klapow, J. C., Roth, D. L., Shuster, J. L, Jr, Bellis, J., Meredith, R., et al. (2005). Randomized pilot of a self-guided internet coping group for women with early-stage breast cancer. Annals of Behavioral Medicine, 30(1), 54-64.

20. Sandgren, A. K., \& McCaul, K. D. (2003). Short-term effects of telephone therapy for breast cancer patients. Health Psychology, $22(3), 310-315$.

21. Gustafson, D. H., Hawkins, R., Pingree, S., McTavish, F., Arora, N. K., Mendenhall, J., et al. (2001). Effect of computer support on younger women with breast cancer. Journal of General Internal Medicine, 16(7), 435-445.

22. Aaronson, N. K., Ahmedzai, S., Bergman, B., Bullinger, M., Cull, A., Duez, N. J., et al. (1993). The European Organization for Research and Treatment of Cancer QLQ-C30: A quality of life instrument for use in international clinical trials in oncology. Journal of the National Cancer Institute, 85, 364-376.

23. Brady, M. J., Cella, D. F., Mo, F., Bonomi, A. E., Tulsky, D. S., Lloyd, S. R., et al. (1997). Reliability and validity of the Functional Assessment of Cancer Therapy-Breast quality-of-life instrument. Journal of Clinical Oncology, 15(3), 974-986.

24. Ferrell, B. R., Dow, K. H., Leigh, S., Ly, J., \& Gulasekaram, P. (1995). Quality of life in long-term cancer survivors. Oncology Nursing Forum, 22(6), 915-922.

25. Holzner, B., Bode, R. K., Hahn, E. A., Cella, D., Kopp, M., Sperner-Unterweger, B., et al. (2006). Equating EORTC QLQC30 and FACT-G scores and its use in oncological research. European Journal of Cancer, 42(18), 3169-3177.

26. Ferrell, B. R., Dow, K. H., \& Grant, M. (1995). Measurement of the quality of life in cancer survivors. Quality of Life Research, 4(6), 523-531.

27. Meneses, K., McNees, P., Azuero, A., Loerzel, V. W., Su, X., \& Hassey, L. A. (2009). Preliminary evaluation of psychoeducational support interventions on quality of life in rural breast cancer survivors after primary treatment. Cancer Nursing, 32(5), 385-397.

28. Park, J. H., Bae, S. H., Jung, Y. S., \& Kim, K. S. (2012). Quality of life and symptom experience in breast cancer survivors after participating in a psychoeducational support program: a pilot study. Cancer Nursing, 35(1), E34-E41. 
29. Rojas, M. P., Telaro, E., Russo, A., Moschetti, I., Coe, L., Fossati, R., et al. (2005). Follow-up strategies for women treated for early breast cancer. Cochrane Database Systematic Reviews, 25(1), CD001768.

30. Chan, C. W., Richardson, A., \& Richardson, J. (2011). Managing symptoms in patients with advanced lung cancer during radiotherapy: results of a psychoeducational randomized controlled trial. Journal of Pain and Symptom Management, 41(2), 347-357.

31. Rottmann, N., Dalton, S. O., Christensen, J., Frederiksen, K., \& Johansen, C. (2010). Self-efficacy, adjustment style and wellbeing in breast cancer patients: a longitudinal study. Quality of Life Research, 19(6), 827-836.

32. (1995). Quality of life and clinical trials. Lancet, 346, 1-2. (Editorial).

33. Beitz, J., Gnecco, C., \& Justice, R. (1996). Quality of life end points in cancer clinical trials: the U.S. Food and Drug Administration perspective. Journal of the National Cancer Institute Monographs, 20, 7-9.

34. Hollen, P. J., \& Gralla, R. J. (1996). Comparison of instruments for measuring quality of life in patients with lung cancer. Seminars in Oncology, 23(2 Suppl 5), 31-40.

35. Mystakidou, K., Tsilika, E., Parpa, E., Smyrnioti, M., \& Vlahos, L. (2005). Assessment of anxiety and depression in advanced cancer patients and their relationship with quality of life. Quality of Life Research, 14, 1825-1833.

36. Moyer, A., Knapp-Oliver, S. K., Sohl, S. J., Schnieder, S., \& Floyd, A. H. (2009). Lessons to be learned from 25 years of research investigating psychosocial interventions for cancer patients. Cancer Journal, 15(5), 345-351.

37. Moyer, A., Sohl, S. J., Knapp-Oliver, S. K., \& Schneider, S. (2009). Characteristics and methodological quality of 25 years of research investigating psychosocial interventions for cancer patients. Cancer Treatment Reviews, 35(5), 475-484.

38. Grunfeld, E., Julian, J. A., Pond, G., Maunsell, E., Coyle, D., Folkes, A., et al. (2011). Evaluating survivorship care plans: Results of a randomized, clinical trial of patients with breast cancer. Journal of Clinical Oncology, 29(36), 4755-4762.

39. Chida, Y., Hamer, M., Wardle, J., \& Steptoe, A. (2008). Do stress-related psychosocial factors contribute to cancer incidence and survival? National Clinical Practice of Oncology, 5(8), 466-475.

40. Smedslund, G., \& Ringdal, G. I. (2004). Meta-analysis of the effects of psychosocial interventions on survival time in cancer patients. Journal of Psychosomatic Research, 57(2), 123-131. 